\title{
Qualitative Analysis of Emotions: Fear and Thrill
}

\author{
Ralf C. Buckley* \\ International Chair in Ecotourism Research, School of Environment, Griffith University, Gold Coast, QLD, Australia
}

People can speak, and this provides opportunities to analyze human emotions using perceived experiences communicated via language, as well as through measurement and imaging techniques that are also applicable to other higher animal species. Here I compare four qualitative methodological approaches to test if, and how, thrill depends on fear. I use eight high-risk, high-skill, real-life outdoor adventure recreation activities to provide the test circumstances. I present data from: $>4000$ person-days of participant observation; interviews with 40 expert practitioners; retrospective autoethnography of 50 critical incidents over 4 decades; and experimental autoethnography of 60 events. Results from different methods are congruent, but different approaches yield different insights. The principal findings are as follows. Individuals differ in their fear and thrill responses. The same individual may have different responses on different occasions.

OPEN ACCESS

Edited by:

Bill Mace,

Trinity College, USA

Reviewed by:

Peter Lewinski,

Kozminski University, Poland Istvan Aranyosi,

Bilkent University, Turkey

*Correspondence: Ralf C. Buckley r.buckley@griffith.edu.au ralf.c.buckley@gmail.com

Specialty section: This article was submitted to Theoretical and Philosophical Psychology, a section of the journal Frontiers in Psychology

Received: 31 March 2016

Accepted: 26 July 2016

Published: 10 August 2016

Citation:

Buckley RC (2016) Qualitative Analysis of Emotions: Fear and Thrill.

Front. Psychol. 7:1187.

doi: 10.3389/fpsyg.2016.01187
Fear boosts performance, but panic causes paralysis. Anxiety or apprehension prior to a risky action or event differs from fear experienced during the event itself. The intensity of pre-event fear generally increases with the immediacy of risk to life, and time to contemplate that risk. Fear must be faced, assessed and overcome in order to act. Thrill can occur either during or after a high-risk event. Thrill can occur without fear, and fear without thrill. Below a lower threshold of perceived risk, thrill can occur without fear. Between a lower and upper threshold, thrill increases with fear. Beyond the upper threshold, thrill vanishes but fear remains. This there is a sawtooth relation between fear and thrill. Perceived danger generates intense focus and awareness. Fear and other emotions can disappear during intense concentration and focus. Under high risk, the usual emotional sequence is fear before the action or event, then focus during the action or event, then thrill, relief, or triumph afterward. The emotionless state persists only during the most intense concentration. For events long enough to differentiate time within the events, fear and thrill can arise and fade in different fine-scale sequences.

Keywords: risk, outdoor, emergency, sawtooth, autoethnography, emotionless

\section{INTRODUCTION}

Neurological and endocrine study of human emotions has advanced greatly in recent years (LeDoux, 2012a,b; Lindquist et al., 2012; Adolphs, 2013). Neuroimaging techniques have been used to correlate emotions with neural signatures, and signatures with emotions (Vytal and Hamann, 2010; Baucom et al., 2012; Hamann, 2012; Lindquist and Barrett, 2012; Kassam et al., 2013; Kragel and LaBar, 2013; Woo et al., 2014; Chang et al., 2015; Howlett and Paulus, 2015). 
Some aspects of emotional psychology, however, cannot yet be examined using laboratory based approaches. These aspects can only be studied through the qualitative analysis of experiences communicated via language. The value of data obtained via autobiographical memory has recently received explicit recognition (Harrison and Loui, 2014; Boccignone and Cordeschi, 2015; Buckley, 2015a; Gardner et al., 2015; Morin et al., 2015). There have been far fewer field tests or methodological advances using these approaches, however, than for approaches based on technological observations and measurements.

In particular, there are some emotional circumstances which are experienced only by a limited number of individuals, and which cannot be reproduced fully through virtual or other experimental means. For example, experimental studies cannot place participants under a real and immediate risk of death. Most experimental studies of anxiety under threat, for example, use only mild threats (Sussman et al., 2015), though some have employed intravenous administration of cholecystokinin to induce panic (de Montigny, 1989; Adolphs, 2013). Recent reviews (e.g., Adolphs, 2013) therefore emphasize the value of studying the conscious experience of emotions as well as the neurological and endocrine aspects.

Here, therefore, I present a comparison between four qualitative approaches in the study of emotions experienced by practitioners of outdoor recreation, during incidents which do involve real risk of immediate death, and which generate fear and thrill. Specifically, I compare findings from retrospective and experimental autoethnography (Buckley, 2015a) against those from participant observation and conventional ethnography (Silverman, 2010; Punch, 2014), which involve the recording of autobiographical memories of research subjects (Gardner et al., 2015).

Whilst many human emotions reflect feelings toward other people (Wilutzky, 2015; Michael, 2016), both fear and thrill are most commonly occasioned by an individual's physical surroundings. Fear may also be occasioned by other persons perceived as threatening, and both fear and thrill may be moderated by the presence or actions of companions. This study, however, focuses on fear and thrill generated by voluntary but potentially dangerous activities carried out during adventure tourism and recreation.

Current understandings of fear and thrill are first reviewed, with particular reference to high-risk outdoor recreation. Many people deliberately take risks, and experience fear, in the quest for thrills. Each of the four qualitative methodological approaches is then presented, and each is compared against current understandings, to test whether it can yield new insights into: the factors influencing experiences of fear and thrill; the timing and trajectory of each under various circumstances; and the relationship between the two distinct emotions.

\section{Fear, Thrill, and Outdoor Recreation}

From an experiential perspective, emotions have been analyzed within three different frameworks: as points in a multidimensional emotional continuum; as a set of $>100$ distinct named emotions in various groups; or as combinations of a small set of basic emotions, commonly recognizable from vocalizations and/or facial and bodily expressions (Johnson-Laird and Oatley, 1989; Meeren et al., 2005; Stets, 2006; Nesse and Ellsworth, 2009; Izard, 2010; Ebner et al., 2012; Graham and LaBar, 2012; Niedenthal and Brauer, 2012; Gu et al., 2013; Kliemann et al., 2013; Kret et al., 2013; Scherer and Meuleman, 2013; Lewinski, 2015).

Fear has an important place in each of these frameworks. Fear is routinely referred to as a basic or fundamental emotion. It is commonly recognizable from facial expressions. It includes a group of related terms such as anxiety, trepidation, apprehension, dread, fright, panic, and terror. The biochemistry and neurophysiology of fear are heavily studied (Chiao et al., 2008; Mujica-Parodi et al., 2009; Haegler et al., 2010; Adams et al., 2011; Agren et al., 2012; Adolphs, 2013; Avila and Lin, 2014; Dehaene, 2014; Zimmer and Clark, 2014; Sussman et al., 2015; White et al., 2016).

At a neurophysiological level, fear can arise through multiple pathways, and fear of pain is different from fear of attack (LeDoux, 2000, 2012a,b; Gross and Canteras, 2012; Adolphs, 2013; Tordjman et al., 2013). Humans also emit and detect fear pheromones (Ackerl et al., 2002; Mujica-Parodi et al., 2009; de Groot et al., 2015; Haviland-Jones et al., 2016). Individuals exposed to these, or to other cues of fear or threat, experience heightened perception and more rapid cognitive processing (Chen et al., 2006; Grillon and Charney, 2011; Grupe and Nitschke, 2013; Robinson et al., 2013; Stout et al., 2013; Jackson et al., 2014; de Valk et al., 2015; Sussman et al., 2015; White et al., 2016) and may take more risks (Maner and Gerend, 2007; Haegler et al., 2010), though this also depends on anger (Habib et al., 2015). When facial expressions of fear (Zhao et al., 2013) are ambiguous, humans also rely on chemical signals to interpret fear in others (Zhou and Chen, 2009; Graham and LaBar, 2012; de Groot et al., 2015).

Reported experiences of fear (Habib et al., 2015) have been described for people of different personalities and professions in various circumstances and situations, from children playing (Sandseter, 2009) to military activities (Fenz and Epstein, 1967; Caputo, 1977; Wallenius et al., 2004; Berko and Erez, 2005; Cohn et al., 2010; Taverniers et al., 2011; Bouchard et al., 2012; Lane et al., 2012; Johnson et al., 2014).

Psychological frameworks for human emotions treat thrill as less fundamental than fear. Related terms include excitement and exhilaration. Emotions such as joy, and triumph or exultation, may often be linked to thrill but are perceived as clearly distinct. There has been less biochemical and neurophysiological research for thrill or excitement than for fear. As with other emotions, thrill is influenced both by genetics (Dmitrieva et al., 2010; Thomson et al., 2013) and neurology (Zald et al., 2008; Kruschwitz et al., 2012). Suggestions of links between thrill and fear are longstanding (Kendrick, 1991; Mura, 2010) but previously untested. In valence-arousal classifications of emotions, fear is considered a negative emotion, and thrill positive. Such links would thus represent a transition from negative to positive valence.

Outdoor adventure recreation (Swarbrooke et al., 2003; Buckley, 2006, 2010a) provides opportunities to study 
powerful human emotions, including fear and thrill, in partially controllable settings (Celsi et al., 1993; Vermeir and Reynier, 2007; Allman et al., 2009; Brymer and Oades, 2009; Buckley, 2012, 2015a,b). Many types of adventure recreation, especially at expert level, involve significant physical risk. They require a high level of learned skill, rapid and precise coordination between sensory perceptions and bodily actions, and an ability to overcome fear. There are many ethnographic analyses of such activities (Michel et al., 1997; Brymer and Oades, 2009; Buckley, 2012), and several relevant neurophysiological studies (Pierson et al., 1999; Haegler et al., 2010; Taverniers et al., 2011; Van Westerloo et al., 2011). For guided commercial adventure tourism and recreation, guides choreograph and manage their clients' emotional responses (Arnould and Price, 1993; Muloin, 1998; Holyfield, 1999; Montag et al., 2005; Sharpe, 2005; Pomfret, 2006; Curtin, 2010; Van Dijk et al., 2011; Wu and Liang, 2011; Buckley, 2012; Houge Mackenzie and Kerr, 2013).

Fear plays a key role in many adventure activities (Holyfield and Fine, 1997; Holyfield, 1999; Jonas, 1999; Beedie and Hudson, 2003; Vermeir and Reynier, 2007; Schnädelbach et al., 2008; Brymer and Oades, 2009; Carnicelli-Filho et al., 2010; Faullant et al., 2011; Buckley, 2012; Brymer and Schweitzer, 2013). This applies especially when fear must be mastered or managed (Fenz and Epstein, 1967; Arnould and Price, 1993; Slanger and Rudestam, 1997; Holyfield, 1999; Sharpe, 2005; Buckley, 2010b; Faullant et al., 2011; Houge Mackenzie and Kerr, 2013).

Thrill and exhilaration are reported by many adventure practitioners (Cater, 2006; Sicard et al., 2007; Tung and Ritchie, 2011; Buckley, 2012; Kim et al., 2012; Chen et al., 2013; Monasterio, 2013; Schlegelmilch and Ollenburg, 2013; Tsaur et al., 2013). High scores on the adventure and thrill-seeking subscale of the sensation-seeking personality scale (Zuckerman, 2007) have been reported, though not uniformly, for outdoor adventure activities including skydiving, paragliding, hanggliding, bungy jumping, rodeo riding, skiing, surfing, and whitewater kayaking (Straub, 1982; Rainey et al., 1992; Campbell et al., 1993; Chirivella and Martinez, 1994; Wagner and Houlihan, 1994; Michel et al., 1997; Zarevski et al., 1998; Gomà-i-Freixanet, 1999; Pierson et al., 1999; Franques et al., 2003; Diehm and Armatas, 2004; Zuckerman, 2007, pp. 97-100; Barbieri and Sotomayor, 2013). For skilled outdoor sport, recreation and adventure, there are ethnographic and autoethnographic analyses of emotions such as fear and thrill in a wide range of activities (Holyfield, 1999; Houge Mackenzie and Kerr, 2013; Buckley, 2014).

No previous formal studies, however, by any method, have set out specifically to examine links between fear and thrill. Analyzing such links is not straightforward. These are human emotions, experienced only by the individuals concerned, often only briefly and under conditions of considerable stress. They are not directly quantifiable by observers. They are not recorded except in individual memories, and indirectly through recorded observations of any outward expressions. Here I report a robust approach that compares four independent sources of data, from different individuals at different times and places: a quadrangulation of qualitative methods.

\section{MATERIALS AND METHODS}

\section{Ethics Statement}

Some of the data presented here were obtained during commercial adventure tours. Assistance and sponsorship of tour operators is gratefully acknowledged. All quotations from individual interviews are used here with the informed written consent of those concerned. All of the research reported here, including that drawn from previous publications by the same author (Buckley, 2006, 2007, 2010a,b, 2012, 2014, 2015a,b), as well as new research conducted specifically for the current publication, was conducted in strict compliance with the research ethics requirements of Griffith University, including adherence to the Griffith University Research Ethics Manual and the Australian National Statement on Ethical Conduct in Human Research, and approvals by the Griffith University Human Research Ethics Committee as required.

\section{Quadrangulation}

Four different methods were compared, a quadrangulation of approaches. These were: participant observation, practitioner interviews, retrospective autoethnography, and experimental autoethnography. All four used voluntary participants in outdoor recreation and adventure tourism. Participant observation, practitioner interviews, and retrospective autoethnography are established methods (Spradley, 1980; Dewalt and Dewalt, 2002; Buzard, 2003; Anderson, 2006; Dauphinee, 2010; Silverman, 2010; Tolich, 2010; Denzin, 2014; Punch, 2014; Buckley, 2015a). Experimental autoethnography is a recently proposed method (Buckley, 2015a), used here for the first time.

The four methods were applied for similar outdoor adventure activities, but over different time periods, in different places, with different subjects. For participant observation, practitioner interviews, and retrospective autoethnography, multiple activities were studied: surfing, sailboarding, and kiteboarding, helicopter snowboarding, whitewater kayaking and rafting, hang-gliding, climbing and mountaineering, off-road driving in remote areas, and watching large and potentially dangerous wildlife. For experimental autoethnography, only two activities were examined, namely surfing and kiteboarding. Each approach provides a different combination of breadth and depth. Results were compared to provide reliability and additional insight.

All observations, document and video analyses, and interviews were conducted and analyzed in accordance with institutional research ethics requirements and national research ethics rules (see Ethics Statement), and with international best practice, including those for interviews, ethnographic, and autoethnographic approaches (Silverman, 2010; Tolich, 2010). Interviewees were informed of the purpose of the research and the identity of the researcher, gave prior informed consent to take part, and gave written permission for individual quotes to be used. Anonymity of all interviewees and participants has been strictly preserved, even when individual participants gave permission to be identified. Some of the data used here were compiled during previously published research (Buckley, 2006, 2007, 2010b, 2012, 2014, 2015a,b), and the re-use and re-analysis 
of the data also complies with institutional ethics requirements (see Ethics Statement).

\section{Participant Observation}

Participant observation data were compiled from $>4,000$ persondays' activities over a period of a decade. Participants ranged in experience from novices to longstanding international guides and instructors. They represent the particular population of people who choose, and are able, to take part in adventure activities. This group is studied here specifically to provide information on links between fear and thrill. Actions, vocalizations and facial expressions were observed directly, and also recorded using multiple hand-held and head-mounted video cameras. As outlined earlier, both fear and thrill are commonly recognizable through facial expressions and vocalizations (Chen et al., 2011; Van den Stock and de Gelder, 2014; Martinez et al., 2015), but these outward expressions can sometimes be suppressed (Gross and Barrett, 2011). Analysis of observations and recordings includes conversations where participants reveal or refer to emotions, which may not have been apparent from actions and expressions alone. Emotions recognized in the field from facial expressions and vocalizations, were necessarily classified only by the author, or by the author and participant where conversations were also involved. Where video recordings were made, emotions were recognized jointly by the entire participant group during playbacks on the same day or at the end of the trip: effectively, a focus-group approach to cross-coding.

\section{Practitioner Interviews}

Expert practitioner interviews were derived ethnographically from semi-structured face-to-face and electronic interviews with skilled guides, instructors and practitioners, over a 3-year period. These individuals have carried out adventure activities over many years, often involving high danger and high risk of immediate death. No inducements were used; interviewees were informed of the research context; procedures followed requirements for research rigor and ethics (Tong et al., 2007; Dauphinee, 2010; Tolich, 2010); and standard emic qualitative analysis approaches were used (Silverman, 2010; Punch, 2014). Ethnographers can use their own experiences, shared with others, to interpret those others' experiences (Hammersley and Atkinson, 2007), because emotional experiences are comprehensible between individuals (Johnson-Laird and Oatley, 1989; Izard, 2010). Individuals reporting similar emotional experiences exhibit similar changes in brain biochemistry and electrical activation, and similar though culturally mediated facial expressions and bodily postures and gestures; and brain parameters and reported emotions respond consistently to experimental manipulation (Frank and Temple, 2009; Niedenthal and Brauer, 2012; Dehaene, 2014). Despite these strong similarities, however, individual sensory and emotional experiences and responses are not identical (JohnsonLaird and Oatley, 1989; Dmitrieva et al., 2010; Gross and Canteras, 2012; Bushdid et al., 2014).

\section{Retrospective Autoethnography}

Retrospective autoethnographic analyses are based on 50 individual incidents experienced over a period of four decades, each involving fear, thrill and related emotions. Each recollection was written out factually at length, reconsidered and mentally replayed multiple times, and examined and compared iteratively, focussing on intensity and timing of fear and thrill. Retrospective analyses use memories, voluntary or involuntary (Berntsen, 2002, 2009; Rubin, 2014). Memories of highly emotional events, also known as critical incidents (Flanagan, 1954) remain intense and detailed for decades, and recollecting the events can re-create the original emotions (Mattley, 2002; Levine and Pizarro, 2004), even when the brain was not focused on the emotions at the time (Avila and Lin, 2014; Dehaene, 2014). Such memories record only specific brief events from a lifetime of experience, but these are precisely the events needed to study high-intensity emotions. Outdoor recreation practitioners have historically claimed that the intense emotions experienced during high-risk, high-skill outdoor recreation are ineffable, impossible to communicate to nonpractitioners (Allman et al., 2009; Brymer and Oades, 2009). Recent approaches, however, have shown that they can be analyzed using retrospective autoethnography (Buckley, 2012, 2015a).

\section{Experimental Autoethnography}

Experimental autoethnography involves deliberately repeating the same actions, and observing one's own emotions as they are experienced (Buckley, 2015a). The observer is still reliant on memory to record the emotions experienced, but it is short rather than long-term, and it is cued by an external trigger rather than an emotional threshold. I used two actions to test the relation between fear and thrill: catching a steep fast wave on a surfboard, and jumping a kiteboard in surf and high wind. Each of these requires learned skills to undertake the maneuvre successfully; and in each case, failure or insufficient skill leads to a wipe-out, a loss of control followed by a fall. In large waves or strong winds, wipeouts can be violent and may cause injury or worse (Buckley, 2012). Each of these maneuvres involves quick, precise, and carefully timed judgements and actions, adjusted through sensory feedback and cognitive control, at subsecond timescales (Buckley, 2012). To track one's emotions during these processes involves switching one's attention, for very brief intervals, from observing action to observing emotion. This technique is not automatic, and has to be learned gradually during multiple repetitions of the same action.

\section{RESULTS}

\section{Participant Observation}

Participant observations were compiled from $>4,000$ persondays activities over a period of a decade. These included: 273 days, $>300$ separate individuals, and $>3000$ participant-days of moderate to high-risk white-water rafting and kayaking, much of it in remote and unknown areas; 83 days, $>90$ individuals, and $>440$ participant-days of wildlife watching in potentially dangerous circumstances, such as watching bear, rhino, elephant, buffalo, lion, leopard, or tiger at close or very close range, on foot or in open vehicles, by night as well as day; 72 days, 46 individuals, 
and 365 participant-days of high-risk surfing on shallow tropical reef breaks; and 70 days, 55 individuals, and 350 participantdays of helicopter snowboarding, including steep, densely treecovered, and heavily cliffed terrain with high avalanche risk at altitudes to $5000 \mathrm{~m}$.

Participant observations provide a relatively coarse understanding of individual emotional experiences. More experienced participants rarely showed fear, even though they freely showed exhilaration and other strong emotions, e.g., when concerned for others' safety. Less experienced participants showed frequent thrill and fear and occasional panic, as revealed by behavior, expressions and vocalizations. Highest fear was shown by first-time participants during unfamiliar high-risk activities. Where the same individuals were observed repeatedly, either on successive days of multi-day activities, or in multiple trips over successive years, incidence of panic decreased as experience increased.

The key result from this approach is that different individuals experience different degrees of fear and thrill, and the same individual may experience different fear and thrill during different events. Participants generally displayed fear or anxiety before a potentially risky event, focus within the event, and thrill afterward. They showed no fear after the event, only relief or triumph; no thrill before it, only anticipation; but sometimes, both fear and thrill during the event itself. Fine-scale sequences of fear and thrill during the event were generally not discernible using this method. That is, it did not prove possible to resolve, using participant observation alone, whether or not fear increases thrill.

\section{Practitioner Interviews}

Individual interview data were derived ethnographically from semi-structured face-to-face and electronic interviews during 2012-2016 with 40 skilled guides, instructors and practitioners: rafters, kayakers, mountaineers, rock and ice climbers, surfers, sailboarders, kiteboarders, and snowboarders. Except for mountaineering and climbing, I had sufficient expertise in each of these activities to be accepted as a competent intermediate practitioner, able to exchange technical and emotional experiences with interviewees. However, my skills have always been well below those of the interviewees themselves. These expert practitioner interviews yielded seven main results, illustrated by the quotations below. The views expressed during these interviews are also reflected in quotations from expert practitioners published in the popular literature of adventure recreation (Davis, 2012; Moriarity, 2012; Yogis, 2013).

(1) For most individuals, fear increases thrill, but only up to a point. "If there's no fear, the achievement is not nearly as fulfilling." "Fear makes the thrills better.. take on being scared and try and conquer it." "The thrill of being scared... the real thrill is conquering the fear." "Fear definitely adds to the enjoyment ... a feeling of accomplishment." "Fear increases thrill sometimes, but not always." "Fear does increase thrill, but there is a fine line between excitement and terror". (2) Only one informant disagreed, a polar explorer who experiences months rather than moments of risk: "I get no thrill from fear." "Moments of fear... add no pleasure."
(3) Fear before an activity, anxiety, is different from fear during an activity, which may include panic. "Fear.. in anticipation.." "there's pre-adventure fear and in the moment' fear..." "Fear can hit suddenly.. like 'I could die here'." (4) Fear must be faced, assessed and overcome. "Stay centred ... lay the fear that you have in the palm of one hand and the risk that you face in the other, don't let go of either." "Fear.. is an alert system for my judgement process." "Overcoming fear so as to act." Panic or terror are experienced as extreme fear which clouds judgment and blocks action. The ability to avoid panic and overcome fear increases with skill and experience.

(5) Fear can disappear during intense concentration. "Fear increases focus and concentration." "During the activity, concentration is so intense that fear drops off." "During the run there's no time for fear." (6) Thrill sometimes occurs after fear, but not always. "Fear comes before the activity. Thrill comes at the end.. a mixture of relief, exultation, satisfaction and adrenaline." "Thrill comes, once I'm in it and once I've completed it." (7) For some interviewees, fear itself is not enjoyable, but thrill is. "Fear itself is not at all pleasurable ... but moving beyond the shackles of fear ... is deeply rewarding."

The key result from this approach is that for most practitioners, fear increases thrill, but only up to a point. Expert practitioners agree that: fear must be faced, assessed and overcome; fear can disappear during intense concentration; and fear is often, but not always, followed by thrill. They differentiate: fear before an activity starts from fear once the activity is under way; fear from risks beyond one's control, from fear associated with one's own capability and performance; and manageable fear, which improves focus, from unmanageable panic, which induces paralysis. The paralyzing consequences of panic match those reported by Adolphs (2013).

\section{Retrospective Autoethnography}

This approach was used here to examine emotions experienced during infrequent dangerous incidents in high-skill high-risk outdoor recreation activities. The activities were: hang-gliding, whitewater kayaking, surfing, off-road driving, snowboarding, surfing, and wildlife watching. Most of the time, these activities produce thrills with little or no risk or fear, and are not recalled as critical incidents. The data for this approach comprise 50 individual incidents, over four decades, which did involve substantial fear, and sometimes also thrill and other powerful emotions. Most incidents lasted only minutes, seconds, or less. A selection of the more extreme incidents are summarized below. Some of these incidents occurred during individual private recreation, others during guided commercial adventure tours. At the time when each incident took place, my experience qualified me in the higher categories of recognized expertise, such as Class $\mathrm{V}$ whitewater and equivalent levels for hang-gliding and snowboarding. However, my expertise has always been far below that of extreme or internationally competitive athletes in any of these activities.

Nine of the incidents involved hang-gliding. In two, I witnessed fatal crashes during cliff take-offs, and then flew off the same cliffs myself. This involved high fear, extreme concentration and intense awareness, overriding thrill. Four involved unusual, 
unanticipated and dangerous circumstances. In one, an error in harness attachment caused over 100 involuntary stalls in $10 \mathrm{~min}$, before I could reach the ground. In another incident, I was hit by a powerful storm front lasting $15 \mathrm{~min}$, and crawled into the nose wires of the hang-glider to maintain tenuous control. Under normal flight conditions this would cause a nosedive and crash. In a third incident, I crashed into a $30 \mathrm{~m}$ tree and fell out backward and upside down, still attached to the hang-glider. In a fourth, a military jet flew beneath my hang-glider, at supersonic speed. There was no thrill in any of these, but very intense awareness. A number of incidents involved powerful thrill as well as fear. These include: rapid height gain in very turbulent thermal lift; semi-inverted acrobatic maneuvres at the limits of the hangglider's flight capabilities; and once, two large eagles flying below my wingtip.

Nine incidents involved surfing. Surfing large steep waves breaking violently over shallow seafloor involves substantial risk of injury, concussion or drowning, especially in crowded conditions over coral reefs. Apprehension and continuous cognitive reappraisal of risk (Dunsmoor et al., 2012) is commonplace whilst paddling into position. The moment of commitment to take-off can generate "heart in mouth" fear, but the actual take-off, which may involve balanced free-fall down the wave face, involves very intense concentration, overriding all emotions. Successful take-offs onto steep fast waves, either long open walls or hollow barrels, yield thrill or joy (Buckley, 2012; Hosany, 2012). Fear and thrill may often be felt on the same wave.

Seven incidents involved backcountry snowboarding, including heliboarding. In one, I triggered a large slab avalanche, and barely escaped by riding at speed over the buckling and cracking slab, and jumping from moving to stationary snow at the edge. There was an instant of fear followed by intense concentration. In another, I made an emergency stop in soft snow, $20 \mathrm{~cm}$ from a 30-m vertical cliff onto rocks. Recalling this still produces a cold sweat. There was no thrill in either of these incidents. Intentional jumps onto steep snow slopes, in contrast, produce high thrill as well as fear. The same applies to high-speed descents down narrow snow-filled couloirs with high avalanche risk, or through dense trees on deep dry powder snow, with risk from tree-wells or tree collisions. There were also many occasions that generated thrill without fear, e.g., riding large open bowls or steep faces in deep dry powder snow with low avalanche risk.

Fifteen incidents involved white-water kayaking through river rapids, waves, and complex turbulent hydraulic features studded with rocks. Most of the time this generates high thrill and low fear. Features such as whirlpools, waterfalls, and more difficult and extended rapids generate fear beforehand, intense concentration during the maneuvre, and high thrill afterward. Paddling rapids that have never been run before (Van Beek, 1998) or where other kayakers have drowned, generates additional fear. Some incidents generated fear without thrill, notably several where I was trapped under water for extended periods. Running long complex rapids, one has time to become aware of both fear and thrill. Other manoeuvres, such as kayak-surfing large standing river waves with low risk, generate thrill without fear.
They may be broadly memorable, but are not recalled in high detail as critical incidents.

Seven incidents involved off-road travel in four-wheel-drive vehicles, days away from any other people, or any chance of rescue. In one, the wheels cut through the crust of a desert salt lake, and I barely escaped. There was a moment of fear, followed by intense emotionless concentration. In another, I became lost in a desert flooded by cyclonic rains. I felt not fear, but exhaustion and determination. When I eventually escaped, I was overcome by powerful and incoherent relief. Other incidents involved driving through windblown dunes with unstable slipfaces and sand-traps, or deep river crossings with water up to the windows of the 4WD. These involved trepidation before starting, intense concentration during the event, and relief and triumph on completion.

Thirteen incidents involved close encounters with large or potentially aggressive animals, either marine or terrestrial. Two humpback whales swam in circles, at close range and high speed, around my unstable racing surfski, several kilometers offshore. This generated thrill but also trepidation. Diving with unaggressive shark species in shallow water, or swimming with seals and sealions, generates thrill rather than fear. Diving with hammerhead sharks at depth or at night, however, does generate fear. Several times I have been within arm's length of lion or elephant, either in an open vehicle or on foot, sometimes at night. This involves very close attention to the animal's behavior, and a certain degree of both fear and thrill. I have been attacked by a baboon, and bitten by a troop of monkeys. On one occasion I and two companions on foot were charged at short range by a black panther, a melanistic leopard. On that occasion I felt no fear but very rapid mental processing.

The principal results from this approach may be summarized as follows. From a methodological perspective, memories are most intense and detailed for incidents involving powerful fear, and the selection of incidents necessarily reflects that. Incidents involving thrill more than fear were far more numerous, but are not recalled so specifically. Acknowledging this intrinsic selectivity, these 50 critical incidents support the conclusions from the expert practitioner interviews, and add further detail. Thrill can be experienced without fear, and fear without thrill. Where both are experienced during the same incident, then fear increases thrill up to a certain threshold, but beyond that, thrill disappears. During brief intense incidents where perceived risk is high and immediate, there is a sequence of emotions or perceptions: fear before the event, emotionless focussed concentration during the event; and thrill, relief, and/or triumph after the event. During more extended incidents, lasting seconds, or minutes, fear can reappear during the event, and fear and thrill may alternate in response to very short-term actions and perceptions.

\section{Experimental Autoethnography}

Both surfing and kiteboarding depend on ambient wind and wave conditions, so they can only be carried out when conditions are appropriate. In addition, only a very small proportion of the time spent surfing and kiteboarding involves take-offs and jumps, respectively. Most of a surfing or kiteboard session, which may 
typically last one or more hours, is spent paddling into position or sailing back and forth. Each individual surf take-off or kite jump typically takes a few seconds at most, often less for surf take-offs, and rarely up to $15 \mathrm{~s}$ for a large jump. For both surf take-offs and kite jumps, control is needed throughout the maneuvre. In each case, however, the crux component is shorter still, and requires precise perceptions and physical movements at timescales of a 10 th of a second. This approach thus generates only a few seconds of data from many hours of activity over an elapsed period of more than 2 years. There are no absolute thresholds of perceived risk, fear, or thrill, distinguishing surf take-offs or kiteboard jumps which provide data, from those which do not. There is thus no absolute count of the number of incidents. There were at least 30 incidents in each activity, however, where both fear and thrill were distinctly recognizable.

Results from experimental autoethnography support those from expert practitioner interviews and retrospective autoethnography, and provide additional insights at finer timescales. In contrast to retrospective autoethnography, the experimental approach is intrinsically biased toward events with lower risk and hence lower fear, since the manoeuvres are deliberate and the author is not an extreme outdoor athlete. In this approach, fear was low, thrill was high, and there were no incidents involving fear without thrill. This approach also supports the sawtooth relation between fear and thrill, where fear boosts thrill up to a certain threshold but not beyond. Whilst many of the incidents used in retrospective autoethnography, however, were beyond that upper threshold, all of the incidents in experimental authoethnography were well below it. The experimental approach also shows that the sawtooth threshold can differ with conditions, for the same activity and individual.

Experimental autoethnography showed that different combinations or categories of fear and thrill may be distinguished. This is consistent with findings from other approaches, but more detailed. On days with a large surf or a strong wind, such as during cyclonic conditions, there is a generalized preevent anxiety and excitement in deciding whether to enter the water at all, and in getting ready to do so. This is essentially a recognition of risk related to ambient conditions, which one judges carefully, assesses against one's own capabilities, and overcomes by paddling out or rigging up. Once one is in the water, paddling the surfboard or riding the kiteboard, there is a very careful attention to conditions, which may include apprehension as well as awareness.

The most significant result from experimental autoethnography is that there are different short-term sequences of emotions, depending on actual outcomes and cognitive sense of control. This confirms analogous suggestions from practitioner interviews and retrospective autoethnography. As one starts the surf take-off or kite jump, the focus is entirely on control, and all emotions disappear. If the maneuver is successful, then this absence of emotion lasts for as long as powerful concentration is needed, throughout the entire maneuver and any subsequent components such as riding a fast and difficult section of a wave, or flying the kite through a jump and landing. Once this is completed, then emotions flood back in a powerful surge of thrill and triumph, which may not be felt until several seconds after the maneuver itself. If the latter part of the wave is easier to ride, or the kite jump involves a smooth maneuver lasting several seconds or longer, however, then one can feel thrill whilst still on the wave or in the air. This corresponds to results from retrospective analytical autoethnography involving snowboarding on long steep slopes, or whitewater kayaking on long rapids. The key finding is that the emotionless state persists as long as full concentration on controlled action is required.

If the maneuver is failing, however, then a powerful burst of "in-the-moment" fear can return instantaneously, overcoming the emotionless sensation. That is, if fear returns because of incipient failure, it does so much faster than thrill is felt following success. This burst of fear, however, is commonly short. Either it vanishes, if one regains control; or it is replaced by concentration on escaping danger and minimizing damage, if one does not. This corresponds to the findings of Noyes and Kletti (1972) that falling climbers "acted with lightning-quickness in accord with accurate judgment". In such cases, there is no subsequent thrill, but only relief once one is out of immediate danger. It also corresponds to the findings from retrospective analytical autoethnography, as above, for the life-threatening incidents related to hanggliding, snowboarding and whitewater kayaking. This result was not available from participant observation or expert practitioner interviews.

\section{Comparisons}

Each of these four methods and datasets demonstrate links between fear and thrill under risk, but each reveals difference insights and nuances in that relation. The principal results from each approach are summarized in Table 1. Considered jointly, these four approaches yield two central conclusions, which do not seem to have been reported previously.

Firstly, the relation between fear and thrill has a sawtooth format. If fear is low, it is possible to experience thrill without fear; and if fear is high, it is possible to experience fear without thrill; but within a certain range of intensity of fear, increased fear leads to increased thrill. As fear increases beyond an upper threshold, fear overwhelms thrill, thrill falls suddenly to zero, and only fear is experienced. The sawtooth threshold may occur at different fear intensities for different people, activities and circumstances. This sawtooth relationship has apparently not been identified previously.

Secondly, during brief intense incidents where perceived risk is high and immediate, there is a sequence of emotions or perceptions: fear before the event, emotionless focussed concentration during the event; and thrill, relief and/or triumph after the event. During more extended incidents, lasting seconds, or minutes, fear can reappear during the event, and fear and thrill may alternate in response to very short-term actions and perceptions. If so, the fear felt during the event is perceived as qualitatively different from fear felt before starting.

There are several apparently novel conclusions derived specifically from retrospective autoethnography. The first result relates to a researcher's ability to recall their own emotions. There are three different measures of the intensity of emotion experienced during a past event (Mattley, 2002; Bywaters et al., 2004; Levine and Pizarro, 2004). The first measure is the 
TABLE 1 | Comparison of results from four qualitative methods in analyzing emotions.

\begin{tabular}{|c|c|c|c|c|}
\hline Methodological approach & $\begin{array}{l}\text { Participant } \\
\text { observation }\end{array}$ & $\begin{array}{l}\text { Practitioner } \\
\text { interviews }\end{array}$ & $\begin{array}{l}\text { Retrospective } \\
\text { autoethno }\end{array}$ & $\begin{array}{l}\text { Experimental } \\
\text { autoethno }\end{array}$ \\
\hline \multicolumn{5}{|l|}{ Scope and data } \\
\hline Activities & 4 & 8 & 7 & 2 \\
\hline Years & 10 & 3 & 40 & 2 \\
\hline Scale & $\begin{array}{l}>4000 \\
\text { person-days }\end{array}$ & $\begin{array}{c}38 \text { expert } \\
\text { practitioners }\end{array}$ & $\begin{array}{l}50 \text { critical } \\
\text { incidents }\end{array}$ & $\begin{array}{l}60 \text { incidents } \\
\text { triggered }\end{array}$ \\
\hline \multicolumn{5}{|l|}{ Principal findings } \\
\hline Individuals differ in fear and thrill responses & $*$ & $*$ & & \\
\hline $\begin{array}{l}\text { Same individual may have different responses on different } \\
\text { occasions }\end{array}$ & $*$ & $*$ & & \\
\hline $\begin{array}{l}\text { Three measures of past emotional intensity correlate only } \\
\text { weakly }\end{array}$ & & & $*$ & \\
\hline Fear boosts performance, panic paralyses & $*$ & * & & \\
\hline Pre-event fear differs from fear during event & & $*$ & $*$ & $*$ \\
\hline $\begin{array}{l}\text { Fear increases with immediacy of risk, and time to } \\
\text { contemplate it }\end{array}$ & & & $*$ & \\
\hline $\begin{array}{l}\text { Fear must be faced, assessed, and overcome in order to } \\
\text { act }\end{array}$ & $*$ & * & $*$ & $*$ \\
\hline Thrill can occur during and/or after event & $*$ & * & $*$ & * \\
\hline Thrill can occur without fear, and fear without thrill & & $*$ & $*$ & * \\
\hline Below a lower threshold, thrill can occur without fear & $*$ & * & $*$ & * \\
\hline $\begin{array}{l}\text { Between a lower and upper threshold, thrill increases with } \\
\text { fear }\end{array}$ & & $*$ & $*$ & \\
\hline Beyond the upper threshold, thrill vanishes but fear remains & & & * & \\
\hline Perceived danger generates intense focus and awareness & & $*$ & $*$ & $*$ \\
\hline Fear can disappear during intense concentration and focus & & * & $*$ & $*$ \\
\hline $\begin{array}{l}\text { Absence of emotion extends only during most intense } \\
\text { concentration }\end{array}$ & & & * & * \\
\hline $\begin{array}{l}\text { Under high risk, emotional sequence is fear, focus, } \\
\text { thrill/relief/triumph }\end{array}$ & & $*$ & $*$ & $*$ \\
\hline
\end{tabular}

* Finding demonstrated by method concerned.

remembered intensity of any involuntary physiological response that occurred during the past event. Involuntary physiological responses to fear include sensations perceived as big-eyes, prickly-skin or falling-stomach. Involuntary responses indicating other emotions include yells of excitement, roars of triumph, or gasps of relief. For example, in one of the off-road driving events, when I finally found a way out after being stuck in the desert, I recall leaping from the vehicle and roaring incoherently and involuntarily at the top of my voice. That is, I recall a very powerful emotion, but the process of remembering it is free of emotion.

The second measure of past emotion is the level of very fine detail in the memory, indicating heightened awareness during the event. For example, for one of the hang-glider cliff takeoffs shortly after another participant had been killed, I have a very intense memory of sun on wildflowers, as I strove to overcome fear before hooking up my harness. The third measure of past emotion is the degree to which involuntary physiological responses are created by the process of recollecting the event. For example, when I recall nearly snowboarding off a cliff onto rocks, the recollection itself produces a cold sweat, though I have no memory of any such response at the time. The analytical autoethnographic approach thus indicates that for the author, the three measures of the intensity of past emotions are not well correlated. If this also applies more generally, it affects all conventional ethnographic studies of emotion.

The second new result from retrospective analytical autoethnography is that the degree of fear is driven by three factors. The first factor is the perceived probability of immediate death. Almost riding a snowboard off a high rock-strewn cliff is an example. The second factor is a longer period to contemplate death before a critical action, even if the risk during that period is low. An example is the period before a hang-glider cliff take-off, or before paddling over a waterfall or into a Class $\mathrm{V}$ whitewater rapid. Sometimes both these factors can occur simultaneously, for example when my hang-glider harness was incorrectly attached and I suffered an extended series of stalls, each with the risk of death. The third factor is that fear can be blocked or overridden by intense concentration on actions to avoid immediate death. This occurred during a number of these incidents, including being trapped underwater whilst surfing or kayaking, or driving a 4WD across a remote arid salt lake. The third of these factors is also supported by expert practitioner interviews, but that approach did not provide data on the first two. Now that these factors have been identified, it would be possible to test them 
more broadly through new expert interviews, as suggested by Buckley (2015a).

The third result from retrospective analytical autoethnography is that there are identifiable sequences of emotions, differing between more and less intense events. For activities with an extended series of moves, fear can intrude suddenly on thrill, depending on cognitive sense of control. Examples include: multiple manoeuvres in a long and complex whitewater rapid; high-speed linked snowboard turns around close-set trees on a steep powder slope; or a long sailboard or kiteboard ride on a large steep wave breaking fast. This fear is of the in-the-moment type. If one regains control, fear disappears again, leaving only a brief aftermath. This matches recent neurological findings (Agren et al., 2012). When the threat of death or other powerful fear is successfully overcome, fear gives way to relief or triumph. Again, this could be tested more broadly through new expert practitioner interviews.

Retrospective and experimental approaches to analytical autoethnography produce different insights. Since the incidents generating highest fear involved high perceived risk, and I have not experienced such incidents deliberately, they are only available for retrospective analysis. Experimental autoethnographic approaches with an external-cue trigger (Buckley, 2015a), in contrast, involve greater focus on thrill, at much lower intensities of risk and fear. This approach provides more reliable and detailed data on changes between emotions over very short time-scales. In addition, the experimental approach can provide successive sets of increasingly focussed observations.

It is difficult for an individual to recall, or describe in a later interview, exactly what sequence of emotions they experienced during a move or manoeuver which is at once difficult, dangerous, exciting, but frightening. In recollection, the various emotions may seem to have been mixed or confused, or to have followed each other at such short timescales that one cannot be sure of the order. It is also difficult for an observer to detect such a sequence, because it occurs too rapidly and may be revealed only weakly through facial expressions, especially if the observer cannot get very close to the person undergoing the experience. By repeating and remembering such experiences oneself, however, and deliberately paying attention to the emotions involved, it is possible to distinguish such a sequence. This is the key benefit of experimental analytical autoethnography in the analysis of emotions (Buckley, 2015a).

Fear and thrill are both extensively studied. The approaches used here add: a distinction between pre-event fear and inthe-moment fear; a distinction between empowering fear and paralyzing panic; and a sawtooth relationship between fear and thrill, with upper and lower thresholds which differ between individuals. Analytical autoethnography, both retrospective and experimental, shows that during high-risk, high-skill activities, fear, and thrill may occur jointly or succeed each other at very short timescales, and that there are multiple different pathways or trajectories, depending on timing, physical circumstances, and perceived control. No other approach has revealed this level of detail.

\section{DISCUSSION}

From the practical perspective, the sequence and drivers of emotions during outdoor adventure recreation are especially valuable if they can be used to analyze and improve emotional control during emergency services and military combat, where it is a great deal more difficult to conduct research. The expert ethnography, in particular, indicates that through practice, one can learn to avoid panic so as to think and act rapidly, decisively, and appropriately under high risk. It appears, though this requires further testing, that this approach only succeeds if the danger and fear are real (cf. Morreall, 1993).

Currently, emergency services and military personnel achieve this by practicing their skills during high-risk events in their actual professions, so-called combat hardening (Fenz and Epstein, 1967; Friedland and Keinan, 1992; Taverniers et al., 2011; Foster and Fletcher, 2013). To reduce injury and mortality, military and emergency services organizations use training approaches which simulate combat or emergencies (Cohn et al., 2010; Bouchard et al., 2012; Johnson et al., 2014). These, however, generally do not involve real fear. The results presented here suggest that it would be more effective to combine such training with practice in overcoming real fear, e.g., through adventure training. Many such organizations do engage in adventure recreation, but not yet for this purpose.

From a research perspective, three significant new avenues arise from the results reported here. The first is that they may help to elucidate how humans perceive the passage of time (Arstila, 2012; Wittmann, 2013; Buckley, 2014; Li and Yuen, 2015). The second is that, especially if it could be coupled with biochemical, neurological and musculoskeletal observations, analytical autoethnography could help to elucidate how we learn physical skills which require very fine coordination of observation and control. There are now mobile electroencephalographic devices such as those manufactured by Emotiv ${ }^{\circledR}$ (2016), but to date these cannot be used in water, especially salt water. I look forward to the day when surf and kite helmets can be fitted with EEGs. Meanwhile, perhaps such a helmet could be constructed for use while snowboarding or bungy jumping.

The third question is: what is the evolutionary origin of thrill? Fear in the face of danger has clear ecological and evolutionary advantages (Nesse and Ellsworth, 2009; Adolphs, 2013; de Valk et al., 2015; Lu et al., 2015). But what is gained through thrill? Thrill drives individuals to perform actions that involve risk and fear. Why should this provide an evolutionary advantage? Is it, perhaps, a mechanism to induce juvenile humans, and perhaps other animal species, to practice the skills they need to survive, thrive, and reproduce in adult life? Humans experience both fear and thrill from a young age (Sandseter, 2009). It appears that as skill increases, the degree of risk and fear needed to generate the same level of thrill also increases (Buckley, 2012). It also appears that when thrill is coupled with the successful performance of a skilled activity under risk, generating what Buckley (2012) referred to as rush, this becomes addictive. These would both be consistent with a strong role in learning.

Similarly, it seems that when circumstances require maximum attention and concentration because of high risk, neither 
fear nor thrill nor any other emotion is experienced at that moment. This is not shock, because it is accompanied either by very rapid mental processing, or complete calm. If emotions have evolved to increase individual survival, why would they disappear at moments of highest risk? Could it be, perhaps, that biochemical aspects of emotion are valuable in long-term behavioral conditioning, but that they interfere with short-term neurological processing, so that when high-speed logical thought is critical for survival, emotions are temporarily shut down? This might be analogous to the recently described mechanism showing interferences between memory and stress (Sekine et al.,

\section{REFERENCES}

Ackerl, K., Atzmueller, M., and Grammer, K. (2002). The scent of fear. Neuroendocrinol. Lett. 23, 79-84.

Adams, R. B., Franklin, R. G., Kveraga, K., Ambady, N., Kleck, R. E., Whalen, P. J., et al. (2011). Amygdala responses to averted vs direct gaze fear vary as a function of presentation speed. Soc. Cogn. Affect. Neurosci. 7, 568-577. doi: $10.1093 /$ scan/nsr038

Adolphs, R. (2013). The biology of fear. Curr. Biol. 23, R79-R93. doi: 10.1016/j.cub.2012.11.055

Agren, T., Engman, J., Frick, A., Bjorkstrand, J., Larsson, E. M., Furmark, T., et al. (2012). Disruption of reconsolidation erases a fear memory trace in the human amygdala. Science 337, 1550-1552. doi: 10.1126/science.1223006

Allman, T., Mittelstaedt, R. D., Martin, B., and Goldenberg, M. (2009). Exploring the motivations of BASE jumpers: extreme sport enthusiasts. J. Sport Tour. 14, 229-247. doi: 10.1080/14775080903453740

Anderson, L. (2006). Analytic autoethnography. J. Contemp. Ethnogr. 35, 373-395. doi: $10.1177 / 0891241605280449$

Arnould, E. J., and Price, L. L. (1993). River magic: extraordinary experience and the extended service encounter. J. Consum. Res. 20, 24-45. doi: 10.1086/209331

Arstila, V. (2012). Time slows down during accidents. Front. Psychol. 3:1-10. doi: 10.3389/fpsyg.2012.00196

Avila, I., and Lin, S. C. (2014). Motivational salience signal in the basal forebrain is coupled with faster and more precise decision speed. PLoS Biol. 12:e0110811. doi: 10.1371/journal.pbio.1001811

Barbieri, C., and Sotomayor, S. (2013). Surf travel behavior and destination preferences: an application of the Serious Leisure Inventory and Measure. Tour. Manag. 35, 111-121. doi: 10.1016/j.tourman.2012.06.005

Baucom, L. B., Wedell, D. H., Wang, J., Blitzer, D. N., and Shinkareva, S. V. (2012). Decoding the neural representation of affective states. Neuroimage 59, 718-727. doi: 10.1016/j.neuroimage.2011.07.037

Beedie, P., and Hudson, S. (2003). Emergence of mountain-based adventure tourism. Ann. Tour. Res. 30, 625-643. doi: 10.1016/S0160-7383(03)00043-4

Berko, A., and Erez, E. (2005). "Ordinary people" and "death work": palestinian suicide bombers as victimizers and victims. Violence Vict. 20, 603-623.

Berntsen, D. (2002). Tunnel memories for autobiographical events: central details are remembered more frequently from shocking than from happy experiences. Mem. Cogn. 30, 1010-1020. doi: 10.3758/bf03194319

Berntsen, D. (2009). Involuntary Autobiographical Memories: An Introduction to the Unbidden Past. Cambridge: Cambridge University Press. doi: 10.1017/CBO9780511575921

Boccignone, G., and Cordeschi, R. (2015). Coping with levels of explanation in the behavioral sciences. Front. Psychol. 6:213. doi: 10.3389/fpsyg.2015.00213

Bouchard, S., Bernier, F., Boivin, E., Morin, B., and Robillard, G. (2012). Using biofeedback while immersed in a stressful videogame increases the effectiveness of stress management skills in soldiers. PLOS ONE 7:e36169. doi: 10.1371/journal.pone.0036169

Brymer, E., and Oades, L. G. (2009). Extreme sports: a positive transformation in courage and humility. J. Humanist. Psychol. 49, 114-126. doi: $10.1177 / 0022167808326199$

Brymer, E., and Schweitzer, R. (2013). Extreme sports are good for your health: a phenomenological understanding of fear and anxiety in extreme sport. J. Health Psychol. 18, 477-487. doi: 10.1177/1359105312446770
2015). More generally, perhaps high-risk adventure activities could contribute to understanding of links between emotion and cognition (Okon-Singer et al., 2015) if we could monitor very short-term changes in brain biochemistry and neurophysiology as individuals undertake activities with high risk, skill, fear and thrill.

\section{AUTHOR CONTRIBUTIONS}

RB conceived, designed and conducted research, wrote article.

Buckley, R. C. (2006). Adventure Tourism. Wallingford: CAB International.

Buckley, R. C. (2007). Adventure tourism products: price, duration, size, skill, remoteness. Tour. Manag. 28, 1428-1433. doi: 10.1016/j.tourman.2006.12.003

Buckley, R. C. (2010a). Adventure Tourism Management. London: Elsevier.

Buckley, R. C. (2010b). Communications in adventure tour products: health and safety in rafting and kayaking. Ann. Tour. Res. 37, 315-332. doi: 10.1016/j.annals.2009.10.011

Buckley, R. C. (2012). Rush as a key motivation in skilled adventure tourism: resolving the risk recreation paradox. Tour. Manag. 33, 961-970. doi: 10.1016/j.tourman.2011.10.002

Buckley, R. C. (2014). Slow time perception can be learned. Front. Psychol. 5:209. doi: 10.3389/fpsyg.2014.00209

Buckley, R. C. (2015a). Autoethnography helps analyse emotions. Front. Psychol. 6, 209. doi: 10.3389/fpsyg.2015.00209

Buckley, R. C. (2015b). Adventure thrills are addictive. Front. Psychol. 6:1915. doi: 10.3389/fpsyg.2015.01915

Bushdid, C., Magnasco, M. O., Vosshall, L. B., and Keller, A. (2014). Humans can discriminate more than 1 trillion olfactory stimuli. Science 343, 1370-1372. doi: $10.1126 /$ science. 1249168

Buzard, J. (2003). On auto-ethnographic authority. Yale J. Crit. 16, 61-92. doi: 10.1353/yale.2003.0002

Bywaters, M., Andrade, J., and Turpin, G. (2004). Determinants of the vividness of visual imagery: the effects of delayed recall, stimulus affect and individual differences. Memory 12, 479-488. doi: 10.1080/09658210444000160

Campbell, J. B., Tyrrell, D. J., and Zingaro, M. (1993). Sensation seeking among whitewater canoe and kayak paddlers. Pers. Individ. Dif. 14, 489-491. doi: 10.1016/0191-8869(93)90319-X

Caputo, P. (1977). Rumor of War. New York, NY: Ballantine Books.

Carnicelli-Filho, S., Schwartz, G. M., and Tahara, A. K. (2010). Fear and adventure tourism in Brazil. Tour. Manag. 31, 953-956. doi: 10.1016/j.tourman.2009.07.013

Cater, C. I. (2006). Playing with risk? Participant perceptions of risk and management implications in adventure tourism. Tour. Manag. 27, 317-325. doi: 10.1016/j.tourman.2004.10.005

Celsi, R., Rose, R., and Leigh, T. (1993). An exploration of high-risk leisure consumption through skydiving. J. Consum. Res. 29, 1-23. doi: 10.1086/209330

Chang, L. J., Gianaros, P. J., Manuck, S. B., Krishnan, A., and Wager, T. D. (2015). A sensitive and specific neural signature for picture-induced negative affect. PLoS Biol. 13:e1002180. doi: 10.1371/journal.pbio.1002180

Chen, D., Katdare, A., and Lucas, N. (2006). Chemosignals of fear enhance cognitive performance in humans. Chem. Senses 31, 415-423. doi: 10.1093/chemse/bjj046

Chen, W., Lander, K., and Liu, C. H. (2011). Matching faces with emotional expressions. Front. Psychol. 2:206. doi: 10.3389/fpsyg.2011.00206

Chen, Y., Guo, Y. Z., Liu, H. B., and Liu, J. (2013). An empirical study in adventure tourism management: a balance between risk and thrill in China. Ann. Grad. Conf. Proc. 18, 31-33.

Chiao, J. Y., Iidaka, T., Gordon, H. L., Nogawa, J., Bar, M., Aminoff, E., et al. (2008). Cultural specificity in amygdala response to fear faces. J. Cogn. Neurosci. 20, 2167-2174. doi: 10.1162/jocn.2008.20151

Chirivella, E. C., and Martinez, L. M. (1994). The sensation of risk and motivational tendencies in sports: an empirical study. Pers. Individ. Dif. 16, 777-786. doi: 10.1016/0191-8869(94)90219-4 
Cohn, J., Weltman, G., Ratwani, R., Chartrand, D., and McCraty, R. (2010). “Stress inoculation through cognitive and biofeedback training," in Proceedings of Interservice/Industry Training, Simulation and Education Conference No. 10293, Orlando, FL, 1-11.

Curtin, S. (2010). Managing the wildlife tourism experience: the importance of tour leaders. Int. J. Tour. Res. 12, 219-236. doi: 10.1002/jtr.747

Dauphinee, E. (2010). The ethics of autoethnography. Rev. Int. Stud. 36, 799-818. doi: 10.1017/S0260210510000690

Davis, S. (2012). Fear. Inside Game, Ep. 2. Available at: https://vimeo.com/39503546 (accessed June 01, 2015).

de Groot, J. H. B., Smeets, M. A. M., and Semin, G. R. (2015). Rapid stress system drives chemical transfer of fear from sender to receiver. PLOS ONE 10:e0118211. doi: 10.1371/journal.pone.0118211

de Montigny, C. (1989). Cholecystokinin tetrapeptide induces panic-like attacks in healthy volunteers: preliminary findings. Arch. Gen. Psychiatry 46, 511-517. doi: 10.1001/archpsyc.1989.01810060031006

de Valk, J. M., Wijnen, J. G., and Kret, M. E. (2015). Anger fosters action. Fast responses in a motor task involving approach movements toward angry faces and bodies. Front. Psychol. 6:1240. doi: 10.3389/fpsyg.2015.01240

Dehaene, S. (2014). Consciousness and the Brain. New York, NY: Viking.

Denzin, N. K. (2014). Interpretive Autoethnography, 2nd Edn. London: Sage.

Dewalt, K. M., and Dewalt, B. R. (2002). Participant Observation: A Guide for Fieldworkers. Walnut Creek, CA: Altamira Press.

Diehm, R., and Armatas, C. (2004). Surfing: an avenue for socially acceptable risk-taking, satisfying needs for sensation seeking and experience seeking. Pers. Individ. Dif. 36, 663-677. doi: 10.1016/S0191-8869(03)00124-7

Dmitrieva, J., Chen, C. S., Greenberger, E., Ogunseitan, O., and Ding, Y. C. (2010). Gender-specific expression of the DRD4 gene on adolescent delinquency, anger and thrill seeking. Soc. Cogn. Affect. Neurosci. 6, 82-89. doi: $10.1093 /$ scan/nsq020

Dunsmoor, J. E., Martin, A., and LaBar, K. S. (2012). Role of conceptual knowledge in learning and retention of conditioned fear. Biol. Psychol. 89, 300-305. doi: 10.1016/j.biopsycho.2011.11.002

Ebner, N. C., Johnson, M. K., and Fischer, H. (2012). Neural mechanisms of reading facial emotions in young and older adults. Front. Psychol. 3:223. doi: $10.3389 /$ fpsyg.2012.00223

Emotiv $^{\circledR}$ (2016). Emotiv EPOC/EPOC+. Available at: https://emotiv.com/epoc (accessed June 01, 2015).

Faullant, R., Matzler, K., and Mooradian, T. A. (2011). Personality, basic emotions, and satisfaction: primary emotions in the mountaineering experience. Tour. Manag. 32, 1423-1430. doi: 10.1016/j.tourman.2011.01.004

Fenz, W. D., and Epstein, S. (1967). Gradients of psychological arousal of experienced and novice parachutists as a function of an approaching jump. Psychosom. Med. 29, 33-51. doi: 10.1097/00006842-19670100000005

Flanagan, J. C. (1954). The critical incident technique. Psychol. Bull. 51, 327-358. doi: $10.1037 / \mathrm{h} 0061470$

Foster, R. E., and Fletcher, J. D. (2013). Toward training transformation. Mil. Psychol. 25, 308-317. doi: 10.1037/h0094971

Frank, C. K., and Temple, E. (2009). Cultural effects on the neural basis of theory of mind. Prog. Brain Res. 178, 213-223. doi: 10.1016/S0079-6123(09) 17815-9

Franques, P., Auriacombe, M., Piquemal, E., Verger, M., Brisseau-Gimenez, S., Grabot, D., et al. (2003). Sensation seeking as a common factor in opioid dependent subjects and high risk sport practicing subjects: a cross-sectional study. Drug Alcohol Depend. 69, 121-126. doi: 10.1016/S0376-8716(02)00309-5

Friedland, N., and Keinan, G. (1992). Training effective performance in stressful situations: three approaches and implications for combat training. Mil. Psychol. 4, 157-174. doi: 10.1207/s15327876mp0403_3

Gardner, R. S., Mainetti, M., and Ascoli, G. A. (2015). Older adults report moderately more detailed autobiographical memories. Front. Psychol. 6:631. doi: 10.3389/fpsyg.2015.00631

Gomà-i-Freixanet, M. (1999). Personality profile of subjects engaged in high physical risk sports. Pers. Individ. Dif. 12, 1087-1093. doi: 10.1016/01918869(91)90038-D

Graham, R., and LaBar, K. S. (2012). Neurocognitive mechanisms of gaze-expression interactions in face processing and social attention. Neuropsychologia 50, 553-566. doi: 10.1016/j.neuropsychologia.2012.01.019
Grillon, C., and Charney, D. R. (2011). In the face of fear: anxiety sensitizes defensive responses to fearful faces. Psychophysiology 48, 1745-1752. doi: 10.1111/j.1469-8986.2011.01268.x

Gross, C. T., and Canteras, N. S. (2012). The many paths to fear. Nat. Rev. Neurosci. 13, 651-658. doi: 10.1038/nrn3301

Gross, J. J., and Barrett, L. F. (2011). Emoption regulation and emotions suppression: one or two depends on your point of view. Emot. Rev. 3, 8-16. doi: $10.1177 / 1754073910380974$

Grupe, D. W., and Nitschke, J. B. (2013). Uncertainty and anticipation in anxiety: an integrated neurobiological and psychological perspective. Nat. Rev. Neurosci. 14, 488-501. doi: 10.1038/nrn3524

Gu, Y., Mai, X., and Luo, Y. J. (2013). Do bodily expressions compete with facial expressions? Time course of integration of emotional signals from the face and the body. PLoS ONE 8:e66762. doi: 10.1371/journal.pone.0066762

Habib, M., Cassotti, M., Moutier, S., Houdé, O., and Borst, G. (2015). Fear and anger have opposite effects on risk seeking in the gain frame. Front. Psychol. 6:253. doi: 10.3389/fpsyg.2015.00253

Haegler, K., Zernecke, R., Kleemann, A. M., Albrecht, J., Pollatos, O., Brückmann, H., et al. (2010). No fear no risk! Human risk behavior is affected by chemosensory anxiety signals. Neuropsychologia 48, 3901-3908. doi: 10.1016/j.neuropsychologia.2010.09.019

Hamann, S. (2012). Mapping discrete and dimensional emotions onto the brain: controversies and consensus. Trends Cogn. Sci. 16, 458-466. doi: 10.1016/j.tics.2012.07.006

Hammersley, M., and Atkinson, P. (2007). Ethnography: Principles in Practice. Oxford: Routledge.

Harrison, L., and Loui, P. (2014). Thrills, chills, frissons, and skin orgasms: toward an integrative model of transcendent psychophysiological experiences in music. Front. Psychol. 5:790. doi: 10.3389/fpsyg.2014.00790

Haviland-Jones, J. M., McGuire, T. R., and Wilson, P. (2016). Testing for individual differences in the identification of chemosignals for fear and happy: phenotypic super-detectors, detectors and non-detectors. PLOS ONE 11:e0154495. doi: 10.1371/journal.pone.0154495

Holyfield, L. (1999). Manufacturing adventure: the buying and selling of emotions. J. Contemp. Ethnogr. 28, 3-32. doi: 10.1177/089124199129023352

Holyfield, L., and Fine, G. A. (1997). Adventure as character work: the collective taming of fear. Symb. Interact. 20, 343-363. doi: 10.1525/si.1997.20.4.343

Hosany, S. (2012). Appraisal determinants of tourist emotional responses. J. Travel Res. 51, 303-314. doi: 10.1177/0047287511410320

Houge Mackenzie, S., and Kerr, J. H. (2013). Stress and emotion at work: an adventure tour guide's experiences. Tour. Manag. 36, 3-14. doi: 10.1016/j.tourman.2012.10.018

Howlett, J. R., and Paulus, M. P. (2015). The neural basis of testable and non-testable beliefs. PLOS ONE 10:e0124596. doi: 10.1371/journal.pone. 0124596

Izard, C. (2010). More meanings and more questions for the term 'emotion'. Emot. Rev. 2, 383-385. doi: 10.1177/1754073910374670

Jackson, M. C., Linden, D. E., and Raymond, J. E. (2014). Angry expressions strengthen the encoding and maintenance of face identity representations in visual working memory. Cogn. Emot. 28, 278-297. doi: 10.1080/02699931.2013.816655

Johnson, D. C., Thom, N. J., Stanley, E. A., Haase, L., Simmons, A. N., Shih, P. A., et al. (2014). Modifying resilience mechanisms in at-risk individuals: a controlled study of mindfulness training in marines preparing for deployment. Am. J. Psychiatry 171, 844-853. doi: 10.1176/appi.ajp.2014.13040502

Johnson-Laird, P. N., and Oatley, K. (1989). The language of emotions: an analysis of a semantic field. Cogn. Emot. 3, 81-123. doi: 10.1080/02699938908408075

Jonas, L. M. (1999). Making and facing danger: constructing strong character on the river. Symb. Interact. 22, 247-268. doi: 10.1525/si.1999.22.3.247

Kassam, K. S., Markey, A. R., Cherkassky, V. L., Loewenstein, G., and Just, M. A. (2013). Identifying emotions on the basis of neural activation. PLoS ONE 8:e66032. doi: 10.1371/journal.pone.0066032

Kendrick, W. (1991). The Thrill of Fear. New York, NY: Grove Press.

Kim, J. H., Ritchie, J. R. B., and McCormick, B. (2012). Development of a scale to measure memorable tourism experiences. J. Trav. Res. 51, 12-25. doi: 10.1177/0047287510385467

Kliemann, D., Rosenblau, G., Bölte, S., Heekeren, H. R., and Dziobek, I. (2013). Face puzzle-two new video-based tasks for measuring explicit and 
implicit aspects of facial emotion recognition. Front. Psychol. 4:376. doi: 10.3389/fpsyg.2013.00376

Kragel, P. A., and LaBar, K. S. (2013). Multivariate pattern classification reveals autonomic and experiential representations of discrete emotions. Emotion 13, 681-690. doi: 10.1037/a0031820

Kret, M., Stekelenburg, J., Roelofs, K., and de Gelder, B. (2013). Perception of face and body expressions using electromyography, pupillometry and gaze measures. Front. Psychol. 4:28. doi: 10.3389/fpsyg.2013.00028

Kruschwitz, J. D., Simmons, A. N., Flagan, T., and Paulus, M. P. (2012). Nothing to lose: processing blindness to potential losses drives thrill and adventure seekers. Neuroimage 59, 2850-2859. doi: 10.1016/j.neuroimage.2011.09.048

Lane, A. M., Bucknall, G., Davis, P. A., and Beedie, C. J. (2012). Emotions and emotion regulation among novice military parachutists. Mil. Psychol. 24, 331-345. doi: 10.1080/08995605.2012.678244

LeDoux, J. E. (2000). Emotion circuits in the brain. Ann. Rev. Neurosci. 23, 155-184. doi: 10.1146/annurev.neuro.23.1.155

LeDoux, J. E. (2012b). Evolution of human emotion: a view through fear. Progr. Brain Res. 195, 431-442. doi: 10.1016/B978-0-444-53860-4.00021-0

LeDoux, J. E. (2012a). Rethinking the emotional brain. Neuron 73, 653-676. doi: 10.1016/j.neuron.2012.02.004

Levine, L. J., and Pizarro, D. A. (2004). Emotion and memory: a grumpy overview. Soc. Cogn. 22, 530-554. doi: 10.1521/soco.22.5.530.50767

Lewinski, P. (2015). Don't look blank, happy, or sad: patterns of facial expressions of speakers in banks' YouTube videos predict video's popularity over time. J. Neurosci. Psychol. Econ. 8, 241-249. doi: 10.1037/npe0000046

Li, W. O., and Yuen, K. S. (2015). The perception of time while perceiving dynamic emotional faces. Front. Psychol. 6:1248. doi: 10.3389/fpsyg.2015.01248

Lindquist, K. A., and Barrett, L. F. (2012). A functional architecture of the human brain: emerging insights from the science of emotion. Trends Cogn. Sci. 16, 533-540. doi: 10.1016/j.tics.2012.09.005

Lindquist, K. A., Wager, T. D., Kober, H., Bliss-Moreau, E., and Barrett, L. F. (2012). The brain basis of emotion: a meta-analytic review. Behav. Brain Sci. 35, 121-143. doi: 10.1017/S0140525X11000446

Lu, Z., Guo, B., Boguslavsky, A., Cappiello, M., Zhang, W., and Meng, M. (2015). Distinct effects of contrast and color on subjective rating of fearfulness. Front. Psychol. 6:1521. doi: 10.3389/fpsyg.2015.01521

Maner, J. K., and Gerend, M. A. (2007). Motivationally selective risk judgments: do fear and curiosity boost the boons or the banes? Organ. Behav. Hum. Decis. Process. 103, 256-267. doi: 10.1016/j.obhdp.2006.08.002

Martinez, L., Falvello, V. B., Aviezer, H., and Todorov, A. (2015). Contributions of facial expressions and body language to the rapid perception of dynamic emotions. Cogn. Emot. 11, 1-11. doi: 10.1080/02699931.2015.1035229

Mattley, C. (2002). The temporality of emotion: constructing past emotion. Symb. Interact. 25, 363-378. doi: 10.1525/si.2002.25.3.363

Meeren, H. K. M., Heijnsbergen, C. C., and de Gelder, B. (2005). Rapid perceptual integration of facial expression and emotional body language. Proc. Natl. Acad. Sci. U.S.A. 102, 16518-16523. doi: 10.1073/pnas.0507650102

Michael, J. (2016). What are shared emotions (for)? Front. Psychol. 7:412. doi: 10.3389/fpsyg.2016.00412

Michel, G., Carton, S., and Jouvent, R. (1997). Sensation seeking and anhedonia in risk taking behaviors: study in bungee jumpers. Encéphale 23, 403-411.

Monasterio, E. (2013). "Personality characteristics in extreme sports athletes: morbidity and mortality in mountaineering and base jumping," in Adventure and Extreme Sports Injuries, eds O. Mei-Dan and M. R. Carmont (London: Springer), 303-314.

Montag, J. M., Patterson, M. E., and Freimund, W. A. (2005). The wolf viewing experience in the Lamar Valley of Yellowstone National Park. Hum. Dimens. Wildl. 10, 273-284. doi: 10.1080/10871200500292843

Moriarity, J. (2012). "Fear is healthy, panic is deadly," in Chasing Mavericks, eds C. Hanson and M. Apted (Los Angeles, CA: 20th Century Fox).

Morin, A., Runyan, J. D., and Brinthaupt, T. M. (2015). Editorial: inner experiences: theory. Measurement, frequency, content, and functions. Front. Psychol. 6:1758. doi: $10.3389 /$ fpsyg.2015.01758

Morreall, J. (1993). Fear without belief. J. Philos. 90, 359-366. doi: 10.2307/2940792 Mujica-Parodi, L. R., Strey, H. H., Frederick, B., Savoy, R., Cox, D., Botanov, Y., et al. (2009). Chemosensory cues to conspecific emotional stress activate amygdala in humans. PLoS ONE 4:e6415. doi: 10.1371/journal.pone. 0006415
Muloin, S. (1998). Wildlife tourism: the psychological benefits of whale watching. Pac. Tour. Rev. 2, 199-213.

Mura, P. (2010). 'Scary . . . but I like it!' Young tourists' perceptions of fear on holiday. J. Tour. Cult. Change 8, 30-49. doi: 10.1080/14766825.2010.482209

Nesse, R. M., and Ellsworth, P. C. (2009). Evolution, emotions and emotional disorders. Am. Psychol. 64, 129-139. doi: 10.1037/a0013503

Niedenthal, P., and Brauer, M. (2012). Social functionality of human emotion. Ann. Rev. Psychol. 63, 259-285. doi: 10.1146/annurev.psych.121208.131605

Noyes, R., and Kletti, R. (1972). The experience of dying from falls. Omega 3, 45-52. doi: 10.2190/96XL-RQE6-DDXR-DUD5

Okon-Singer, H., Hendler, T., Pessoa, L., and Shackman, A. J. (2015). The neurobiology of emotion-cognition interactions: fundamental questions and strategies for future research. Front. Hum. Neurosci. 9:58. doi: 10.3389/fnhum.2015.00058

Pierson, A., le Houezec, U., Fossaert, A., Dubal, S., and Jouvent, R. (1999). Frontal reactivity and sensation seeking: an ERP study in skydivers. Prog. Neuropsychopharm. Biol. Psychol. 23, 447-463. doi: 10.1016/S02785846(99)00008-1

Pomfret, G. (2006). Mountaineering adventure tourists: a conceptual framework for research. Tour. Manage. 27, 113-123. doi: 10.1016/j.tourman.2004.08.003

Punch, K. (2014). Introduction to Social Research: Quantitative and Qualitative Approaches, 3rd Edn. London: Sage.

Rainey, D. W., Amunategui, F., Agocs, H., and Larick, J. (1992). Sensation seeking and competitive trait anxiety among rodeo athletes. J. Sport Behav. 15, 307-317.

Robinson, O. J., Vytal, K., Cornwell, B. R., and Grillon, C. (2013). The impact of anxiety upon cognition: perspectives from human threat of shock studies. Front. Hum. Neurosci. 7:203. doi: 10.3389/fnhum.2013.00203

Rubin, D. C. (2014). How quickly we forget. Science 346, 1058-1059. doi: $10.1126 /$ science.aaa2341

Sandseter, E. B. H. (2009). Children's expressions of exhilaration and fear in risky play. Contemp. Issues Early Child. 10, 92-106. doi: 10.2304/ciec.2009.10.2.92

Scherer, K. R., and Meuleman, B. (2013). Human emotion experiences can be predicted on theoretical grounds: evidence from verbal labeling. PLoS ONE 8:e58166. doi: 10.1371/journal.pone.0058166

Schlegelmilch, F., and Ollenburg, C. (2013). Marketing the adventure: utilizing the aspects of risk/fear/thrill to target the youth traveller segment. Tour. Rev. 68, 44-54. doi: 10.1108/TR-03-2013-0010

Schnädelbach, H., Egglestone, S. R., Reeves, S., Benford, S., Walker, B., and Wright, M., (2008). Performing Thrill: Designing Telemetry Systems and Spectator Interfaces for Amusement Rides. Available at: http://www.cs.nott.ac.uk/ pszsre/ papers/chi2008/author_version.pdf (accessed June 01, 2015).

Sekine, Y., Zyryanova, A., Crespillo-Casado, A., Fischer, P. M., Harding, H. P., and Ron, D. (2015). Mutations in a translation initiation factor identify the target of a memory-enhancing compound. Science 348, 1027-1030. doi: $10.1126 /$ science.aaa6986

Sharpe, R. (2005). "Going above and beyond": the emotional labor of adventure guides. J. Leis. Res. 37, 29-50.

Sicard, B., Jouvre, E., and Blin, O. (2007). "Extreme risk-taking and decision making," in Decision Making in Complex Environments, eds M. Cook, J. Noyes, and J. Masakowski (Burlington, VT: Ashgate), 53-62.

Silverman, D. (2010). Qualitative Research, 3rd Edn. London: Sage.

Slanger, E., and Rudestam, E. (1997). Motivation and disinhibition in high risk sports: sensation seeking and self efficacy. J. Res. Personal. 31, 355-374. doi: 10.1006/jrpe.1997.2193

Spradley, J. (1980). Participant Observation. New York, NY: Holt, Rinehart and Winston.

Stets, J. (2006). Emotion and Sentiments. Boston, MA: Springer. doi: 10.1007/0-38736921-x_13

Stout, D. M., Shackman, A. J., and Larson, C. L. (2013). Failure to filter: anxious individuals show inefficient gating of threat from working memory. Front. Hum. Neurosci. 7:58. doi: 10.3389/fnhum.2013.00058

Straub, W. F. (1982). Sensation seeking among high- and low-risk male athletes. J. Sport Psychol. 4, 246-253.

Sussman, T. J., Szekely, A., Hajcak, G., and Mohanty, A. (2015). It's all in the anticipation: how perception of threat is enhanced in anxiety. Emotion 16, 320-327. doi: 10.1037/emo0000098

Swarbrooke, J., Beard, C., Leckie, S., and Pomfret, G. (2003). Adventure Tourism: The New Frontier. Oxford: Butterworth-Heinemann. 
Taverniers, J., Smeets, T., Lo Bue, S., Syroit, J., Van Ruysseveldt, J., Pattyn, N., et al. (2011). Visuo-spatial path learning, stress, and cortisol secretion following military cadets' first parachute jump: the effect of increasing task complexity. Cogn. Affect. Behav. Neurosci. 11, 332-343. doi: 10.3758/s13415-011-0043-0

Thomson, C. J., Hanna, C. W., and Carlson, S. R. (2013). The -521C/T variant in the dopamine-receptor gene (DRD4) is associated with skiing and snowboarding behavior. Scand. J. Med. Sci. Sports 23, 108-113. doi: 10.1111/sms.12031

Tolich, M. (2010). A critique of current practice: ten foundational guidelines for autoethnographers. Qual. Health Res. 20, 1599-1610. doi: 10.1177/1049732310376076

Tong, A., Sainsbury, P., and Craig, J. (2007). Consolidated Criteria for Reporting Qualitative Research (COREQ): A 32-Item Checklist for Interview and Focus Groups. Available at: http://intqhc.oxfordjournals.org/content/intqhc/19/6/349. full.pdf (accessed June 01, 2015).

Tordjman, K., Constantini, N., and Hackney, A. C. (2013). "Endocrine aspects and responses to extreme sports," in Adventure and Extreme Sports Injuries, eds O. Mei-Dan and M. R. Carmont (London: Springer), 315-324. doi: 10.1007/9781-4471-4363-5_15

Tsaur, S. H., Lin, W. R., and Liu, J. S. (2013). Sources of challenge for adventure tourists: scale development and validation. Tour. Manage. 38, 85-93. doi: 10.1016/j.tourman.2013.03.004

Tung, V. W. S., and Ritchie, J. R. B. (2011). Exploring the essence of memorable tourism experiences. Ann. Tour. Res. 38, 1367-1386. doi: 10.1016/j.annals.2011.03.009

Van Beek, S. (1998). The power of one. Explor. J. 1998, 22-29.

Van den Stock, J., and de Gelder, B. (2014). Face identity matching is influenced by emotions conveyed by face and body. Front. Hum. Neurosci. 8:53. doi: 10.3389/fnhum.2014.00053

Van Dijk, P. A., Smith, L. D. G., and Cooper, B. K. (2011). Are you real? An evaluation of the relationship between emotional labour and visitor outcomes. Tour. Manage. 32, 39-45. doi: 10.1016/j.tourman.2009.11.001

Van Westerloo, D., Choi, G., Löwenberg, E. C., Truijen, J., de Vos, A. F., Endert, E., et al. (2011). Acute stress elicited by bungee jumping suppresses human innate immunity. Mol. Med. 17, 180-188. doi: 10.2119/molmed.2010.00204

Vermeir, K., and Reynier, V. (2007). "Style" de pratique, sentiment d'appartenance communautaire et représentations sociales du risque en stations de sports d'hiver. Loisir Soc. 29, 347-376. doi: 10.1080/07053436.2006.10707723

Vytal, K., and Hamann, S. (2010). Neuroimaging support for discrete neural correlates of basic emotions: a voxel-based meta-analysis. J. Cogn. Neurosci. 22, 2864-2885. doi: 10.1162/jocn.2009.21366

Wagner, A. M., and Houlihan, D. D. (1994). Sensation seeking and trait anxiety in hang-glider pilots and golfers. Pers. Individ. Dif. 16, 975-977. doi: 10.1016/01918869(94)90240-2

Wallenius, C., Larsson, G., and Johansson, C. R. (2004). Military observers' reactions and performance when facing danger. Mil. Psychol. 16, 211-229. doi: $10.1207 /$ s15327876mp1604_1
White, C. N., Skokin, K., Carlos, B., and Weaver, A. (2016). Using decision models to decompose anxiety-related bias in threat classification. Emotion 16, 196-207. doi: $10.1037 / \mathrm{emo} 0000109$

Wilutzky, W. (2015). Emotions as pragmatic and epistemic actions. Front. Psychol. 6:1593. doi: 10.3389/fpsyg.2015.01593

Wittmann, M. (2013). The inner sense of time: how the brain creates a representation of duration. Nat. Rev. Neurosci. 14, 217-223. doi: $10.1038 / \mathrm{nrn} 3452$

Woo, C. W., Koban, L., Kross, E., Lindquist, M. A., Banich, M. T., Ruzic, L., et al. (2014). Separate neural representations for physical pain and social rejection. Nat. Commun. 5:5380. doi: 10.1038/ncomms6380

$\mathrm{Wu}$, G. H. J., and Liang, R. D. (2011). The relationship between whitewater rafting experience formation and customer reactions: a flow theory perspective. Tour. Manage. 32, 317-325. doi: 10.1016/j.tourman.2010. 03.001

Yogis, J. (2013). The Fear Project. New York, NY: Rodale.

Zald, D. H., Cowan, R. L., Riccardi, P., Baldwin, R. M., Ansari, M. S., et al. (2008). Midbrain dopamine receptor availability is inversely associated with novelty-seeking traits in humans. J. Neurosci. 28, 14372-14378. doi: 10.1523/JNEUROSCI.2423-08.2008

Zarevski, P., Marusic, I., Zolotic, S., Bunjevac, T., and Vukosav, Z. (1998). Contribution of Arnett's inventory of sensation seeking and Zuckerman's sensation seeking scale to the differentiation of athletes engaged in highand low-risk sports. Pers. Individ. Dif. 25, 763-768. doi: 10.1016/S01918869(98)00119-6

Zhao, K., Yan, W. J., Chen, Y. H., Zuo, X. N., and Fu, X. (2013). Amygdala volume predicts inter-individual differences in fearful face recognition. PLoS ONE 8:e74096. doi: 10.1371/journal.pone.0074096

Zhou, W., and Chen, D. (2009). Fear-related chemosignals modulate recognition of fear in ambiguous facial expressions. Psychol. Sci. 20, 177-183. doi: 10.1111/j.1467-9280.2009.02263.x

Zimmer, C., and Clark, R. (2014). Secrets of the brain. Nat. Geogr. 28-58. Available at: http://ngm.nationalgeographic.com/2014/02/brain/zimmer-text

Zuckerman, M. (2007). Sensation Seeking and Risky Behavior. Washington DC: American Psychological Association. doi: 10.1037/11555-000

Conflict of Interest Statement: The author declares that the research was conducted in the absence of any commercial or financial relationships that could be construed as a potential conflict of interest.

Copyright (c) 2016 Buckley. This is an open-access article distributed under the terms of the Creative Commons Attribution License (CC BY). The use, distribution or reproduction in other forums is permitted, provided the original author(s) or licensor are credited and that the original publication in this journal is cited, in accordance with accepted academic practice. No use, distribution or reproduction is permitted which does not comply with these terms. 